\title{
A unipolar nano-diode detector with improved performance using high-k material SiNx
}

DOI:

10.1088/1361-6641/aae2f5

\section{Document Version}

Accepted author manuscript

Link to publication record in Manchester Research Explorer

\section{Citation for published version (APA):}

Zhang, L., Zhou, H., Zhang, J., Wang, Q., Zhang, Y., \& Song, A. (2018). A unipolar nano-diode detector with improved performance using high-k material SiN $x$. Semiconductor Science and Technology, 33, [114016]. https://doi.org/10.1088/1361-6641/aae2f5

\section{Published in:}

Semiconductor Science and Technology

\section{Citing this paper}

Please note that where the full-text provided on Manchester Research Explorer is the Author Accepted Manuscript or Proof version this may differ from the final Published version. If citing, it is advised that you check and use the publisher's definitive version.

\section{General rights}

Copyright and moral rights for the publications made accessible in the Research Explorer are retained by the authors and/or other copyright owners and it is a condition of accessing publications that users recognise and abide by the legal requirements associated with these rights.

\section{Takedown policy}

If you believe that this document breaches copyright please refer to the University of Manchester's Takedown Procedures [http://man.ac.uk/04Y6Bo] or contact uml.scholarlycommunications@manchester.ac.uk providing relevant details, so we can investigate your claim.

\section{OPEN ACCESS}




\title{
Unipolar nano-diode detector with improved performance using high-k material $\mathrm{SiN}_{x}$
}

\author{
Linqing Zhang ${ }^{1}$, Haiping Zhou ${ }^{2}$, Jiawei Zhang ${ }^{1}$, Qingpu Wang ${ }^{3}$, Yifei Zhang ${ }^{3}$ and \\ Aimin Song ${ }^{1,3,4}$ \\ ${ }^{1}$ School of Electrical and Electronic Engineering, University of Manchester, Manchester, United \\ Kingdom \\ ${ }^{2}$ School of Engineering, University of Glasgow, Glasgow, United Kingdom \\ ${ }^{3}$ The Center of Nanoelectronics and School of Microelectronics, Shandong University, Jinan, China \\ ${ }^{4}$ The State Key Laboratory of Crystal Materials, Shandong University, Jinan, China \\ E-mail: yifeizhang@sdu.edu.cn, A.Song@ manchester.ac.uk
}

\begin{abstract}
The performance of a solid-state planar nano-diode, namely self-switching diode (SSD), is improved by depositing a 100 -nm-thick $\mathrm{SiN}_{\mathrm{x}}$ film with high dielectric constant (high-k) into the insulating nano-trenches. The $\mathrm{SiN}_{\mathrm{x}}$ film grown by using plasma-enhanced chemical vapour deposition (PECVD) can enhance the electric field coupling over the trenches and thus increase the accumulated charges for field effect. In this case, the current-voltage nonlinearity is improved significantly and the responsivity of high frequency rectification is also increased by a factor of almost one order up to $100 \mathrm{GHz}$. In addition, compared to the device without $\mathrm{SiN}_{\mathrm{x}}$ coating, the low frequency noise of the proposed diode is suppressed dramatically. The improved responsivity and noise-equivalent power (NEP) of 11 SSDs in parallel with $\mathrm{SiN}_{\mathrm{x}}$ coating are $110 \mathrm{~V} / \mathrm{W}$ at $50 \mathrm{GHz}$ and $180 \mathrm{pW} / \mathrm{Hz}^{1 / 2}$, which are comparable to the state-of-the-art data of reported SSD arrays.
\end{abstract}

Keywords: Self-switching diode, $\operatorname{SiN}_{\mathrm{x}}$, High-k, Nano rectifier

\section{Introduction}

Terahertz technologies have been envisaged to have promising applications in medical and security imaging, pharmaceutical compound analysis, and radio astronomy etc. [1]. However, the frequency band is often called 'terahertz gap' due to a lack of high performance solid-state terahertz detectors and emitters at room temperature. Among the reported novel detectors [2, 3], a nano-scale self-switching diode (SSD) is a promising candidate for real applications. An SSD based on GaAs/AlGaAs heterostructure containing a two-dimensional electron gas (2DEG) has been shown to operate at frequencies up to $1.5 \mathrm{THz}$ without any $\mathrm{DC}$ bias at room temperature [4]. Successful detection of free-space terahertz radiation between 1.3 and $2.5 \mathrm{THz}$ at low temperatures from 10 to $150 \mathrm{~K}$ has also been demonstrated by SSDs fabricated using an InGaAs/InP 2DEG wafer [5]. In addition, SSDs have been realized using other semiconductor materials, such as InAs/AlAs [6], GaN/AlGaN [7] and 2D materials [8]. For terahertz detectors, responsivity and noise performance are two most important factors. By connecting about 2000 SSDs in parallel, the thermal noise of the SSD array was significantly reduced and the noise-equivalent power (NEP) was improved to a value of $64 \mathrm{pW} / \mathrm{Hz}^{1 / 2}$ [9], among the lowest ones of the reported terahertz detectors.

Additionally, modelling and simulation of SSD have been carried out intensively [10-13]. A number of simulations predicted that the SSD performance can be improved significantly if its nano-trenches are filled with high-k materials [14-17]. However, to the best of our knowledge, no fabricated device has been reported to demonstrate this yet. On the other hand, high-k materials have already been widely used as a substitute for $\mathrm{SiO}_{2}$ in electronics to achieve high mobility, low threshold voltage and low leakage [18-21]. Examples are $\mathrm{HfO}_{2}$ [22], $\mathrm{Si}_{3} \mathrm{~N}_{4}$ [23], $\mathrm{SiO}_{\mathrm{x}} \mathrm{N}_{\mathrm{y}}$ [24] and 
HfSiON [25]. In this work, SSD arrays are fabricated on 2 DEG $\mathrm{In}_{53} \mathrm{Ga}_{47}$ As substrate with high-k $\mathrm{SiN}_{\mathrm{x}}$ filling for their nano-trenches, achieving high responsivity and low noise. Such improvement is highly desired for terahertz detection at room temperature.

\section{Experiment}

An InGaAs/InAlAs 2DEG wafer from IQE Inc. was used to fabricate the SSDs. The 2DEG embedded in the InGaAs/InAlAs heterostructure is located $25 \mathrm{~nm}$ below the surface, as depicted in Figure 1(a). The carrier density and electron mobility of the 2DEG are $1.3 \times 10^{12} \mathrm{~cm}^{-2}$ and $10,400 \mathrm{~cm}^{2} / \mathrm{V} \cdot \mathrm{s}$ at $300 \mathrm{~K}$, respectively. The relatively high electron mobility of the InGaAs/InAlAs based 2DEGs is beneficial for high frequency detection. The active area of the diode, consisting of asymmetric nanochannels defined with nano-trenches, was fabricated using electron-beam lithography, as shown in Figure 1(b). The SSD structure was then transferred into the substrate by bromine-based wet etching, which stops at the InAlAs buffer layer. The depth of the insulation trench is around $50 \mathrm{~nm}$ measured by atomic force microscopy (AFM), and the width is about $150 \mathrm{~nm}$. The trenches can force the electrons to flow only through the nanochannels.

(a)

\begin{tabular}{|c|c|}
\hline $\ln _{53} \mathrm{Ga}_{47} \mathrm{As}$ & $10 \mathrm{~nm}$ \\
\hline $\mathrm{In}_{52} \mathrm{Al}_{48} \mathrm{As}$ & $5 \mathrm{~nm}$ \\
\hline $\mathrm{N}+\mathrm{DD}$ & $6.0 \mathrm{e} 18$ \\
\hline $\mathrm{In}_{52} \mathrm{Al}_{48} \mathrm{As}$ & $10 \mathrm{~nm}$ \\
\hline $\mathrm{Tn}_{53} \overline{\mathrm{Ga}} \overline{\mathrm{a}_{47}} \overline{\mathrm{As}}$ & $--15 \overline{\mathrm{nm}}$ \\
\hline $\mathrm{In}_{52} \mathrm{Al}_{48} \mathrm{As}$ & $300 \mathrm{~nm}$ \\
\hline Substrate & $\operatorname{In} P$ \\
\hline
\end{tabular}

(b)

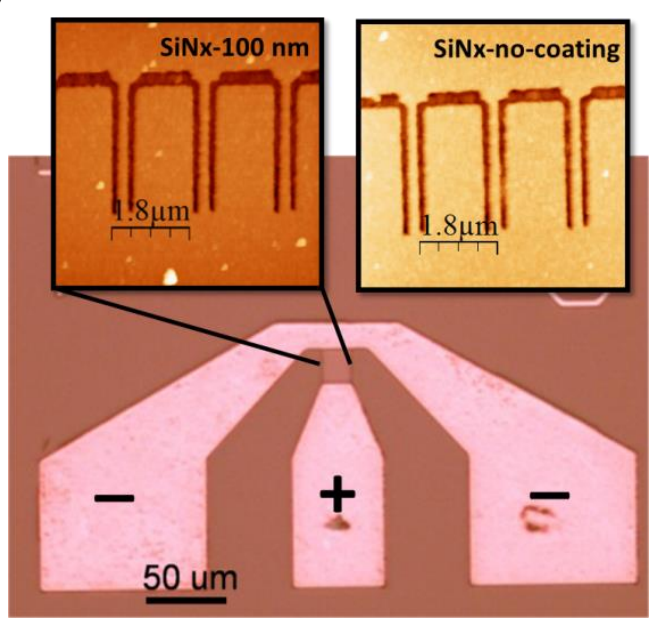

Figure 1. (a) Structure of InGaAs/InAlAs 2DEG wafer. (b) AFM images of the etched SSD array with and without $\operatorname{SiN}_{x}$ coating with co-planar waveguide ohmic contacts. The SSD channel is $3 \mu \mathrm{m}$ long and $215 \mathrm{~nm}$ wide.
With the device unbiased, the effective channel is actually narrower than the geometric width due to the depletion region at the etched boundaries, which is introduced by the charges of surface states. The amount of surface charges could be affected by surface roughness, charge states, Fermilevel pinning and surface treatments [26]. The effective channel of the SSD can be widened or narrowed with forward or reverse bias respectively. This corresponds to the nonlinearity and thus a high-frequency rectification.

11 SSDs are accommodated in parallel on a mesa structure, as shown in Figure 1(b), which are fed by using a co-planar waveguide (CPW) with an impedance of $50 \Omega$ for rectification characterisation. The signal and gap width of the $\mathrm{CPW}$ is $60 \mu \mathrm{m}$ and $55 \mu \mathrm{m}$, respectively. To reduce the ohmic contact resistance, the electrodes are fabricated with $\mathrm{Au} / \mathrm{Ge} / \mathrm{Ni} / \mathrm{Au}$. The measured ohmic contact resistance is $0.86 \Omega . \mathrm{mm}$ and the specific resistance is $4 \times 10^{-5} \Omega . \mathrm{cm}^{2}$.

$\mathrm{SiN}_{\mathrm{x}}$ has been widely used as passivation for electronic devices, such as the field effect transistor (FET) [27] and high-electron-mobility transistor (HEMT) [28]. To improve the performance of the SSDs, the $\mathrm{SiN}_{\mathrm{x}}$ coating was grown by plasma-enhanced chemical vapour deposition (PECVD), which offers excellent dielectric properties of the deposited and conformed step coverage [29]. The deposition was carried out with $\mathrm{SiH}_{4}, \mathrm{NH}_{3}$ and $\mathrm{N}_{2}$ at flow rates of 10, 16, $170 \mathrm{sccm}$, respectively, at $300{ }^{\circ} \mathrm{C}$. The thickness of the $\operatorname{SiN}_{x}$ coating was $100 \mathrm{~nm}$, namely twice that of the trench depth, so that the trenches were completely filled. The proposed device is nominated as ' $\mathrm{SiN}_{\mathrm{x}}-100 \mathrm{~nm}$ ' while another device without coating is nominated ' $\mathrm{SiN}_{\mathrm{x}}$-no-coating'. These will be used for comparison in the following sections.

\section{Results and discussion}

\subsection{I-V Characterisation}

The devices were characterised at room temperature in the dark, by using Agilent E5270B semiconductor analyser. As the positive forward bias was increased, the current first increased rapidly and then quasi-linearly due to the series resistance, as shown in Figure 2(a). With a negative bias, the reverse current exists as the channel is not completely pinched off. Compared to that of the uncoated device, both the forward and reverse currents of the coated device are clearly increased, as shown in Figure 2(a). This is as expected from the enhanced field coupling over the trenches and the reduced electric field strength on the channel. However, note that the device nonlinearity, given by $[I(V)+I(-V)] / 2$, is significantly enhanced particularly at low bias values, which are conditions desired for high-frequency rectification, as plotted in Figure 2(b). For instance, the nonlinearity of the current-voltage (I-V) curve is enhanced by a factor of about 18 at $0.1 \mathrm{~V}$. 
(a)

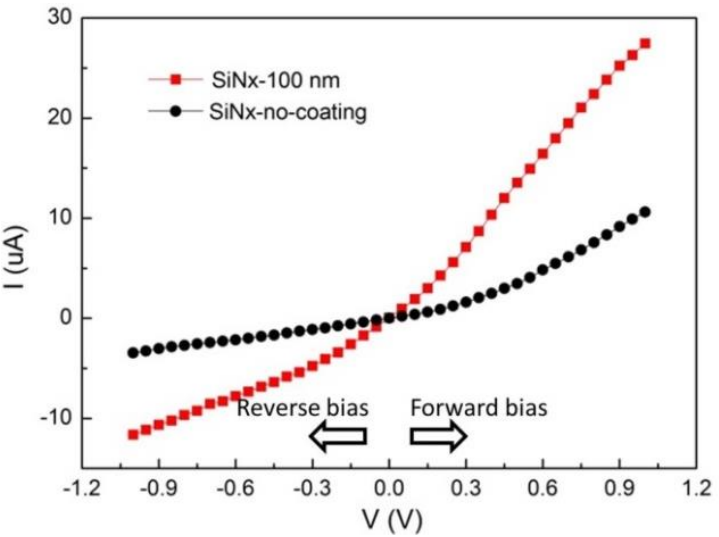

(b)

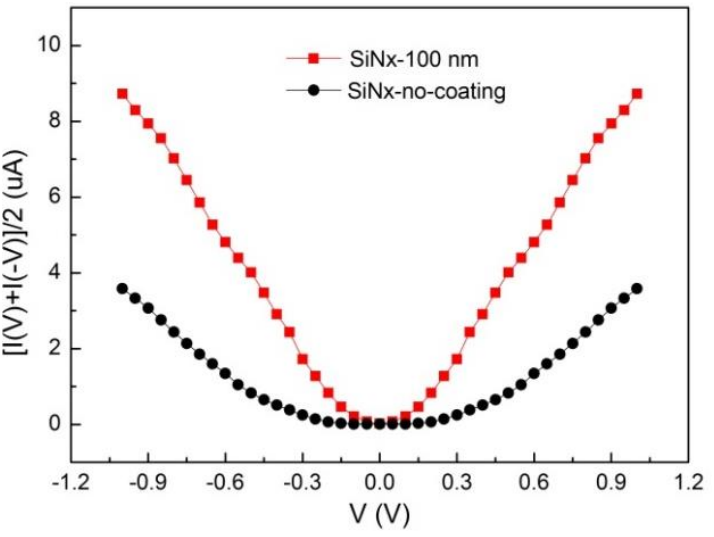

Figure 2. (a) The I-V characteristics of $\mathrm{SiN}_{\mathrm{x}}-100 \mathrm{~nm}$ and $\mathrm{SiN}_{\mathrm{x}}$-no-coating. (b) The extracted nonlinear component of the $\mathrm{I}-\mathrm{V}$ curves in (a).

\subsection{RF Characterisation}

An Agilent 8510XF vector network analyser (VNA) providing continuous frequency coverage from $45 \mathrm{MHz}$ to $100 \mathrm{GHz}$ was employed for high-frequency rectification measurement. The DC bias was provided with Keithley 2400 source measure unit through a bias- $\mathrm{T}$, and the input power was calibrated before being fed into SSDs device. Figure 3(a) illustrates the rectified output voltages of the devices at zero bias. It can be seen that the output voltage of the device with $\mathrm{SiN}_{\mathrm{x}}$ coating is clearly higher than that of its uncoated counterpart, which reveals the strong enhancement of the responsivity. Figure 3(b) shows the output voltage as a function of input power measured at $50 \mathrm{GHz}$ and zero bias. The output voltage is proportional to the input power, which corresponds to the square-law operation of the device. The extrinsic responsivity of the devices can be calculated by dividing the measured output voltage by the input power ($5.5 \mathrm{dBm})$. The extrinsic responsivity of the device $\mathrm{SiN}_{\mathrm{x}}-$ $100 \mathrm{~nm}$ is $110 \mathrm{~V} / \mathrm{W}$ at $50 \mathrm{GHz}$, which is much higher than that of $\mathrm{SiN}_{\mathrm{x}}$-no-coating, 6.99 V/W. By integrating thousands of SSDs with high-k coating in parallel, the input impedance can further reduce from $33.3 \mathrm{k} \Omega$ (the zero-bias resistance) down to hundreds of ohms for better impedance matching and noise performance [9].

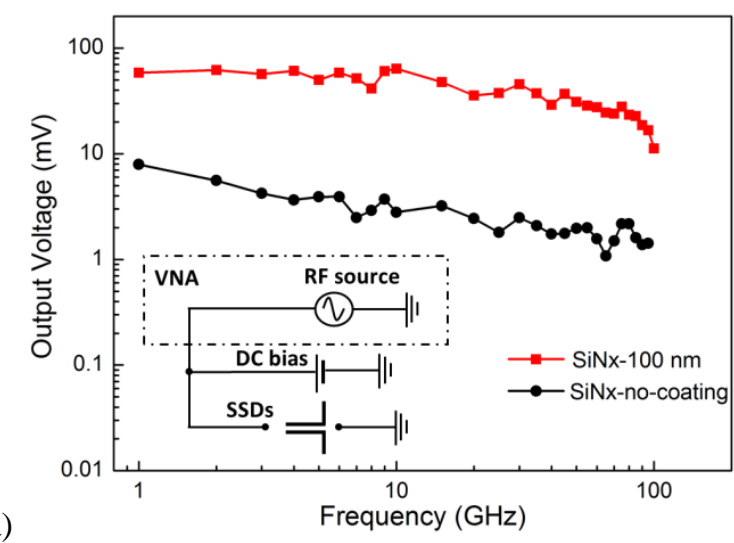

(b)

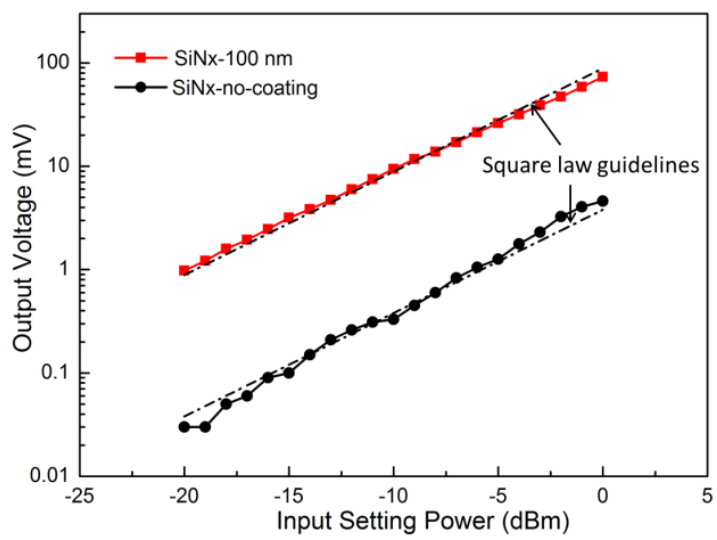

Figure 3. (a) Comparison of RF performance of $\mathrm{SiN}_{\mathrm{x}}-100 \mathrm{~nm}$ and $\mathrm{SiN}_{\mathrm{x}}$-no-coating up to $100 \mathrm{GHz}$ with an input power of $5.5 \mathrm{dBm}$ at zero bias, and schematic representation of the RF measurement setup. (b) Output voltage as a function of input power for both devices measured at zero bias and $50 \mathrm{GHz}$.

\subsection{Low-frequency Noise Measurement}

The low-frequency noise performance of the devices was characterized by using a two-channel cross-correlation measurement [30, 31], as depicted in Figure 4(a). The twochannel cross-correlation method reduces the uncorrelated noise, but it cannot get rid of the input equivalent current noise of an operational amplifier (op-amp), which is mixed with the device noise in the noise measurement [30]. A low noise op-amp, TL1169, was then used to amplify the input noise signal due to its low input current noise of $1 \mathrm{fA} / \mathrm{Hz}^{1 / 2}$ [32]. The highest frequency is approximately $10 \mathrm{kHz}$, which is limited by the amplifier bandwidth. The low-frequency noise is dominated by thermal and/or flicker noise $[9,33]$. The measured noise spectral plot of the $\mathrm{SiN}_{\mathrm{x}}-100 \mathrm{~nm}$ and $\mathrm{SiN}_{\mathrm{x}}$-no-coating at $32.5 \mathrm{nA}$ bias and zero bias current is shown in Figure 4(b). It can be observed that the voltage noise significantly decreases by a factor of more than 10 times with the $\mathrm{SiN}_{\mathrm{x}}$ coating.

The voltage power spectral density is proportional to $1 / f^{\beta}$ at a certain current bias according to Equation 1 [9, 34]. 


$$
S_{V}(f)=\frac{\alpha_{H}}{N f^{\beta}} I^{2} R^{2}
$$

where $I$ is the bias current, $R$ is the resistance of the device under test, $N$ is the total number of carriers in the SSD array, $f$ is the frequency and $\alpha_{H}$ is the Hooge's constant. The constant $\beta$ is 0.96 by fitting the curve in Figure 4(b), which means the low frequency noise is dominated by $1 / f$ noise. The dependence between the voltage noise, $\sqrt{S_{V}(f)}$, and the bias current at frequency of $100 \mathrm{~Hz}$ is shown in Figure 4(c). The voltage noise increases linearly as the bias current enlarges then the increase slows down. The linear dependency can be explained by Hooge's empirical equation, indicating that the low frequency noise is caused by the carrier mobility fluctuation [35]. At relatively high current bias, the effective channel width could increase slightly, leading to the slight decrease of the slope in Figure 4(c) according to Equation 2, which is expressed as

$$
S_{V}(f)=\frac{1}{M^{3}} \frac{1}{n^{3} q^{2} \mu_{n}^{2}} \frac{L}{W_{e f f}{ }^{3}} \frac{\alpha_{H}}{f^{\beta}} I^{2}
$$

where $n$ is the electron concentration, $M$ is the number of SSDs in parallel, $L$ is the channel length of the SSD, $q$ is the electron charge, and $\mu_{n}$ is the 2DEG electron mobility and $W_{\text {eff }}$ is the effective channel width, which is $215 \mathrm{~nm}$ in this paper.

(a)
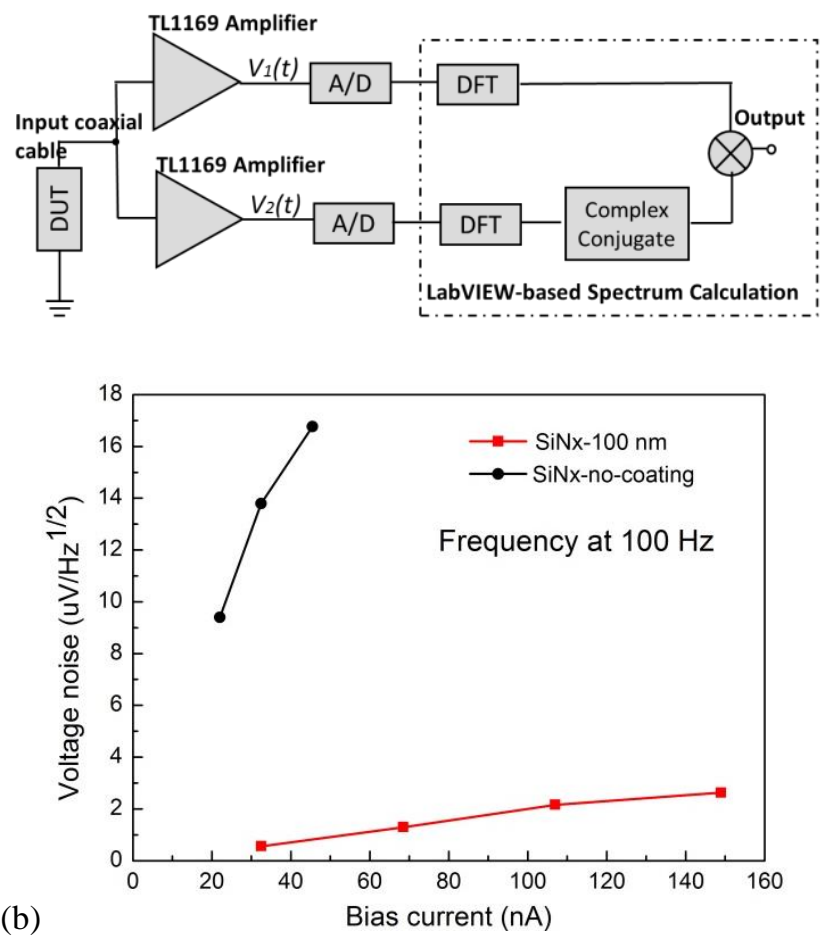

(c)

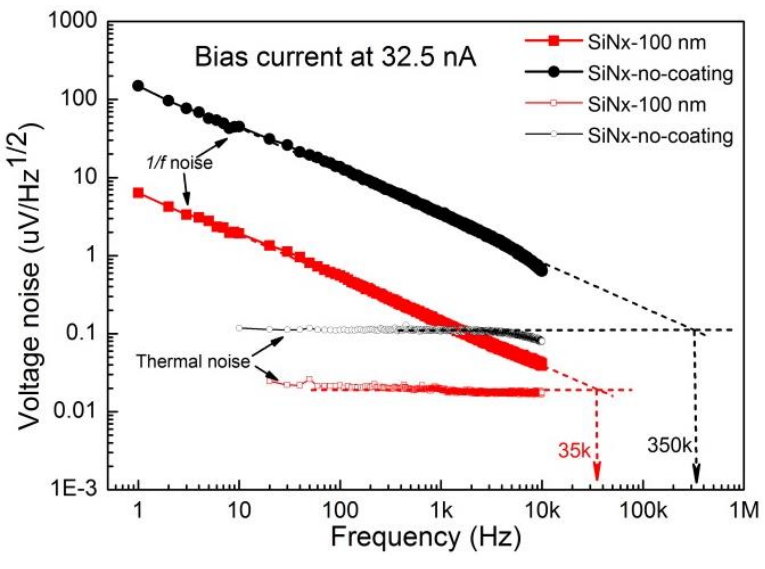

Figure 4. (a) Schematic system set-up of the two-channel cross-correlation measurement. (b) Voltage noise of device $\mathrm{SiN}_{\mathrm{x}}-100 \mathrm{~nm}$ and $\mathrm{SiN}_{\mathrm{x}}$-no-coating at $32.5 \mathrm{nA}$ and zero bias at room temperature with determination of the corner frequencies. (c) The linear dependence of voltage noise on the bias current at $100 \mathrm{~Hz}$.

For the devices $\mathrm{SiN}_{\mathrm{x}}-100 \mathrm{~nm}$ and $\mathrm{SiN}_{\mathrm{x}}$-no-coating, the channel length is $3 \mu \mathrm{m}$, and the zero-bias resistance is 33.3 and $616 \mathrm{k} \Omega$, respectively. The device without coating has a Hooge's constant of $3.7 \times 10^{-3}$, which is lower than that of the device with coating $\left(5.1 \times 10^{-2}\right)$. Although the Hooge's constant of the device $\mathrm{SiN}_{\mathrm{x}}-100 \mathrm{~nm}$ is larger, the significant reduction of the its resistance results in the reduced overall noise. In this case, l/f noise is caused by the scatteringinduced carrier mobility fluctuations [36, 37]. The deposition of $\mathrm{SiN}_{\mathrm{x}}$ may introduce more traps at the interface in contact with the semiconductor. The increased interface states may cause more scattering, such as lattice scattering [38] and Coulomb scattering [39], resulting in a higher Hooge's constant. Using thermal evaporation may be able to decrease the traps and surface states caused by the PECVD coating process [40]. The corner frequency, shown as the cross point of the flick noise and thermal noise in Figure 4(a), which is 35 and $350 \mathrm{kHz}$ for the device $\mathrm{SiN}_{\mathrm{x}}-100 \mathrm{~nm}$ and $\mathrm{SiN}_{\mathrm{x}}$-nocoating at $32.5 \mathrm{nA}$ bias current, respectively. This indicates that $\mathrm{SiN}_{\mathrm{x}}$ coating effectively suppresses the voltage noise and, thus, reduces the corner frequency. When the detected signal is smaller, the corner frequency could be further reduced for chopping [9]. NEP is another important metric of the sensitivity. When the frequency is above the corner frequency, thermal noise dominates the noise spectrum. Then the NEP is determined by thermal noise which is proportional to the resistance of SSDs. It is found that the extrinsic NEP significantly decreased by two orders of magnitude from $1.6 \times 10^{-8}$ to $1.8 \times 10^{-10} \mathrm{~W} / \mathrm{Hz}^{1 / 2}$ after $\mathrm{SiN}_{\mathrm{x}}$ coating. The NEP can be further reduced by integrating more SSDs due to the lower total resistance as well as the thermal noise. The responsivity and NEP of the 11 SSDs in parallel 
are $110 \mathrm{~V} / \mathrm{W}$ at $50 \mathrm{GHz}$ and $180 \mathrm{pW} / \mathrm{Hz}^{1 / 2}$ which are comparable to results achieved by integrating thousands of SSDs on an InGaAs/InAlAs 2DEG wafer [9].

\section{Conclusion}

We proposed to use $\mathrm{SiN}_{\mathrm{x}}$ coating to improve the detection properties of the nano-rectifier, i.e. SSD. SSD arrays with nano-trenches coated with and without $\mathrm{SiN}_{\mathrm{x}}$ were fabricated, characterized, and compared. Those coated achieved high responsivity and low noise, agreeing with reported simulation results. They exhibit enhanced nonlinearity and output current, the parameters desired for room temperature $\mathrm{THz}$ detectors. This improvement is due to electric field coupling over the trenches causing an increase in the accumulated charges for the field effect. High-frequency measurement from $45 \mathrm{MHz}$ to $100 \mathrm{GHz}$ was carried out, which reveals a consistent improvement of the responsivity. The reduced low frequency noise, corner frequency and NEP demonstrate a good passivation of high- $\mathrm{K} \mathrm{SiN}_{\mathrm{x}}$ for the SSDs.

\section{Acknowledgements}

The authors wish to acknowledge the National Key Research and Development Program of China (Grant Nos. 2016YFA0301200 and 2016YFA0201800), the European Commission through the FP7 ROOTHz project under Grant Agreement No. 243845, the National Natural Science Foundation of China (Grant Nos. 61701283 and 11404115), Engineering and Physical Sciences Research Council (EPSRC) (Grant No. EP/N021258/1), China Postdoctoral Science Foundation funded project (Grant Nos. 2018T110689, 2017M622201, and 2016M590634), the Key Research and Development Program of Shandong Province (Grant Nos. 2017GGX10121 and 2017GGX10111), Postdoctoral Innovation Program of Shandong Province (Grant No. 20171006), Suzhou Planning Projects of Science and Technology (Grant No. SYG201616), and the Fundamental Research Funds of Shandong University (Grant No. 2016WLJH44) for supporting this work.

\section{References}

[1] Ferguson B and Zhang X-C 2002 Materials for terahertz science and technology Nat. Mater. 1 26-33

[2] Balocco C et al. 2005 Microwave detection at $110 \mathrm{GHz}$ by nanowires with broken symmetry Nano Lett. 5 1423-1427

[3] Song A M, Missous M, Omling P, Peaker A R, Samuelson L, and Seifert W 2003 Unidirectional electron flow in a nanometer-scale semiconductor channel: A self-switching device Appl. Phys. Lett. 83 1881-1883

[4] Balocco C, Kasjoo S R, Lu X F, Zhang L Q, Alimi Y, Winnerl S, and Song A M 2011 Room-temperature operation of a unipolar nanodiode at terahertz frequencies Appl. Phys. Lett. 98223501

[5] Balocco C et al. $2008 \mathrm{THz}$ operation of asymmetricnanochannel devices J. Phys.: Condens. Matter 20384203
[6] Westlund A, Sangare P, Ducournau G, Nilsson P-A, Gaquiere C, Desplanque L, Wallart X, and Grahn J 2013 Terahertz detection in zero-bias InAs self-switching diodes at room temperature Appl. Phys. Lett. 103133504

[7] Sangare P et al. 2013 Experimental demonstration of direct terahertz detection at room-temperature in $\mathrm{AlGaN} / \mathrm{GaN}$ asymmetric nanochannels J. Appl. Phys. 113034305

[8] Al-Dirini F, Skafidas, E and Nirmalathas, A 2013 Graphene self switching diodes with high rectification ratios 13th IEEE International Conference on Nanotechnology

[9] Balocco C, Kasjoo S R, Zhang L Q, Alimi Y, and Song A M 2011 Low-frequency noise of unipolar nanorectifiers Appl. Phys. Lett. 99113511

[10] Westlund A et al. 2014 On the effect of $\delta$-doping in selfswitching diodes Appl. Phys. Lett. 105093505

[11] Millithaler J F, Iñiguez-de-la-Torre I, González T, Mateos J, Sangaré P, Ducournau G, and Gaquière C 2013 Noise in terahertz detectors based on semiconductor nanochannels 22nd International Conference on Noise and Fluctuations (ICNF)

[12] Iñiguez-De-La-Torre I, Rodilla H, Mateos J, Pardo D, Song M, and Gonzlez T 2009 Terahertz tunable detection in selfswitching diodes based on high mobility semiconductors: InGaAs, InAs and InSb J. Phys: Conf. Ser.

[13] Westlund A et al. 2015 Optimization and small-signal modeling of zero-bias InAs self-switching diode detectors Solid-State Electron. 104 79-85

[14] Zakaria N F, Kasjoo S R, Zailan Z, Isa M M, Taking S, and Arshad M K M 2017 Permittivity and temperature effects on rectification performance of self-switching diodes with different geometrical structures using two-dimensional device simulator Solid-State Electron. 138 16-23

[15] Farhi G, Morris D, Charlebois S A, and Raskin J P 2011 The impact of etched trenches geometry and dielectric material on the electrical behaviour of silicon-on-insulator self-switching diodes Nanotechnology 22435203

[16] Iñiguez-De-La-Torre I, Mateos J, Pardo D, Song A M, and González T 2009 Noise and terahertz rectification linked by geometry in planar asymmetric nanodiodes Appl. Phys. Lett. 94093512

[17] Iniguez-de-la-Torre I, Mateos J, Pardo D, Song A M, and Gonzá lez T 2010 Enhanced Terahertz detection in selfswitching diodes Int. J. Numer. Model. Electron. Networks Devices Fields 23 301-314

[18] Frank M M, Kim S, Brown S L, Bruley J, Copel M, Hopstaken M, Chudzik M, and Narayanan V 2009 Scaling the MOSFET gate dielectric: From high-k to higher-k? Microelectron. Eng. 86 1603-1608

[19] P. K. Saikia U J M, P. Saikia, B. Baishya, R Sarma and D. Saikia, 2012 Low threshold voltage pentacene OTFTs with $\mathrm{La}_{2} \mathrm{O}_{3}$ gate insulating layer using TSD Chiang Mai Journal of Science 39 263-269

[20] Kauerauf T, Govoreanu B, Degraeve R, Groeseneken G, and Maes H 2005 Scaling CMOS: Finding the gate stack with the lowest leakage current Solid-State Electron. 49 695-701

[21] Kaushal V, Î̃niguez-De-La-Torre I, Gonzalez T, Mateos J, Lee B, Misra V, and Margala M 2012 Effects of a high-k dielectric on the performance of III-V ballistic deflection transistors IEEE Electron Device Lett. 33 1120-1122

[22] Hurley P K et al. 2008 Interface Defects in $\mathrm{HfO}_{2}, \mathrm{LaSiO}_{x}$, and $\mathrm{Gd}_{2} \mathrm{O}_{3}$ High-k/Metal-Gate Structures on Silicon $J$. Electrochem. Soc. 1558

[23] Yeo Y-C, King T-J, and Hu C 2003 MOSFET Gate Leakage Modeling and Selection Guide for Alternative Gate 
Dielectrics Based on Leakage Considerations IEEE Trans. Electron Devices $\mathbf{5 0} 9$

[24] Pey K L, Ranjan R, Tung C H, Tang L J, Lo V L, Lim K S, Selvarajoo T A L, and Ang D S 2005 Breakdowns in high-k gate stacks of nano-scale CMOS devices Microelectron. Eng. 80 353-361

[25] Lukyanchikova N, Garbar N, Kudina V, Smolanka A, Put S, Claeys C, and Simoen E 2009 On the 1/f noise of triple-gate field-effect transistors with high-k gate dielectric Appl. Phys. Lett. 95032101

[26] Xu K-Y, Wang G, and Song A 2007 Electron transport in self-switching nano-diodes J. Comput. Electron. 6 59-62

[27] Kim H, Thompson R M, Tilak V, Prunty T R, Shealy J R, and Eastman L F 2003 Effects of SiN passivation and highelectric field on AlGaN-GaN HFET degradation IEEE Electron Device Lett. 24 421-423

[28] Sung-Woon M, Jongsub L, Deokwon S, Sungdal J, Hong Goo C, Heejae S, Jeong Soon Y, John T, and Sungwon D R 2014 High-voltage GaN-on-Si hetero-junction FETs with reduced leakage and current collapse effects using $\mathrm{SiN}_{\mathrm{x}}$ surface passivation layer deposited by low pressure CVD Jpn. J. Appl. Phys. 53 08NH02

[29] Iliescu C, Tay F E H, and Wei J 2006 Low stress PECVD$\mathrm{SiN}_{\mathrm{x}}$ layers at high deposition rates using high power and high frequency for MEMS applications J. Micromech. Microeng. 16 869-874

[30] Sampietro M, Fasoli L, and Ferrari G 1999 Spectrum analyzer with noise reduction by cross-correlation technique on two channels Rev. Sci. Instrum. 70 2520-2525

[31] Crupi F, Giusi G, and Pace C 2007 Two-channel amplifier for high-sensitivity voltage noise measurements IEEE Instrumentation and Measurement Technology Conference Proceedings (IMTC)

[32] Manfredi P F, Speziali V, and Svelto F 1994 Extremely lownoise amplifier for interfacing active devices to instruments for spectral analysis Rev. Sci. Instrum. 65 3848-3852

[33] Duran H C, Ren L, Beck M, Py M A, Ilegems M, and Bachtold W 1997 Low frequency noise in dry and wet etched InAlAs/InGaAs HEMTs IEEE International Symposium on Compound Semiconductors

[34] van der Ziel A 1988 Unified presentation of 1/f noise in electron devices: fundamental 1/f noise sources Proc. IEEE 76 233-258

[35] Dutta P and Horn P M 1981 Low-frequency fluctuations in solids: 1/f noise Rev. Mod. Phys. 53 497-516

[36] Ghibaudo G, Roux O, Nguyen-Duc C, Balestra F, and Brini J 1991 Improved analysis of low frequency noise in field-effect MOS transistors Phys. Status Solidi A $\mathbf{1 2 4} 11$

[37] Hooge F N 1976 1/f Noise Physica 83B 10

[38] Jindal R P, and Ziel A 1981 Model for mobility fluctuation 1/f noise Appl. Phys. Lett. 38 290-291

[39] Shahriar Rahman M, Morshed T, Devireddy S P, Celik-Butler Z, Quevedo-Lopez M A, Shanware A, and Colombo L 2008 Effect of nitrogen incorporation on 1/f noise performance of metal-oxide-semiconductor field effect transistors with HfSiON dielectric J. Appl. Phys. 103033706

[40] Zhu G, Wang H, Yiming W, Feng X, and Song A 2016 Performance enhancement of AlGaN/AlN/GaN high electron mobility transistors by thermally evaporated $\mathrm{SiO}$ passivation Appl. Phys. Lett 109113503 